УДК 615.281.9

http://dx.doi.org/10.26787/nydha-2686-6838-2020-22-6-55-60

\title{
APPROACHES TO ANTIBIOTIC THERAPY IN PATIENTS WITH CAL- CULOUS PYELONEPHRITIS, UNDERGOING TREATMENT IN THE UROLOGY DEPARTMENT OF BELGOROD MUNICIPAL HOSPITAL
}

\author{
Malorodova ${ }^{1,2}$ T.N., Stepenko ${ }^{2}$ Yu.V., Anikanova ${ }^{2}$ T.V., Mikhailova ${ }^{2}$ Yu.A. \\ ${ }^{1}$ Belgorod Municipal Hospital No.2, Belgorod, Russian Federation \\ ${ }^{2}$ Belgorod State University, Belgorod, Russian Federation
}

\section{ПОДХОДЫ К СТАРТОВОЙ АНТИБАКТЕРИАЛЬНОЙ ТЕРАПИИ У БОЛЬНЫХ КАЛЬКУЛЕЗНЫМ ПИЕЛОНЕФРИТОМ, НАХОДЯЩИХСЯ НА ЛЕЧЕНИИ В ОТДЕЛЕНИИ УРОЛОГИИ В ГОРОДСКОЙ БОЛЬ- НИЦЕ №2 Г.БЕЛГОРОДА}

\author{
Малородова $^{1,2}$ T.Н., Степенко Ю.В., Аниканова ${ }^{2}$ T.В., Михайлова ${ }^{2}$ Ю.А. \\ ${ }^{1}$ ОГБУЗ "Городская больница №2 г. Белгорода", г. Белгород, Российская Федерация \\ ${ }^{2}$ ФББОУ ВО «Белгородский государственный нащиональный исследовательский университет», \\ г. Белгород, Российская Федерачия
}

\footnotetext{
Аннотация. В настоящеее время, при относительно хорошей изученности этиологической структуры возбудителей пиелонефрита, возникает быстрый рост резистентности к антибактериальных препаратам у возбудителей, выделяемым при данном заболевании. Целью данного исследования является изучение структуры выделенных микроорганизмов и их чувствительности к антибиотикам у пациентов с калькулезным пиелонефритом для определения стартовой терапии у пациентов, находящихся на лечении в отделении урологии Городской больниць №2, г. Белгород. В ретроспективное фармакоэпидемиологическое исследование включались истории болезни пациентов старие 18 лет с установленным диагнозом «калькулезный пиелонефрит», проходивиих лечение в отделении урологии Городской больницьь №2, г. Белгород за период 2017-2019 гг. Выделены 723 итамма из мочи у 2410 пациентов. Проводилась идентификачия и тестирование чувствительности выделенных штаммов микроорганизмов методом дисковой диффузии, результать интерпретировались в соответствии с критериями EUCAST. Основными патогенными микроорганизмами являлись Escherichia coli, представленная в 64,7\% случаев, Klebsiella spp. - в 22,4\% случаев. Наиболее активными антибиотиками являлись меропенем, эртапенем, амикачин, фосфомицин. Получена достоверная разница между чувствительностью итаммов Enterobacteriaceae, выделенных у пачиентов, не получавших антибактериальную терапию, и итаммов Enterobacteriaceae, выделенными у пачиентов, получавиих терапию антибактериальными препаратами последние 3 месяия.

Заключение. Для стартовой терапии у пациентов с калькулезным пиелонефритом, не получавших лечение антибактериальными препаратами последние 3 месяца, в урологи ческом отделении Городская больница №2 г.Белгорода рекомендован цеефотаксим, ципрофлоксацин и левофлоксаичн; у пациентов, получавших лечение антибактериальными препаратами последние 3 месяча эффективны амикацин, фосфомицин, пиперациллин/тазобактам, цеефоперазон / сульбактам, карбапенемы.
}

Abstract. The aim of a research study the structure of the isolated microorganisms and their sensitivity to antibiotics in patients with calculous pyelonephritis, as well as to determine the sensitivity to antibacterial drugs for starting therapy in patients undergoing treatment in the Urology Department of Belgorod Municipal Hospital No.2. It was a retrospective pharmacoepidemiological study, which was analyzed medical records of patients over 18 years old with calculous pyelonephritis, who were treated in the Urology Department of Belgorod Municipal Hospital No.2 during 20172019. It were isolated 723 strains $(32.1 \%)$ from urine of $2410 \mathrm{pa}$ tients. Susceptibility testing was done by disk diffusion method and interpreted according to the EUCAST criteria. The main pathogens were Escherichia coli, represented in $64.7 \%$ of the isolates, followed by Klebsiella spp. in $22.4 \%$ of isolates. The most active antibiotics for isolated strains of Enterobacteriaceae were meropenem, ertapenem, amikacin, and phosphomycin. A significant difference was obtained between the sensitivity of Enterobacteriaceae strains isolated in 2019 who did not receive antibacterial therapy and Enterobacteriaceae strains isolated from patients, were treated with antibacterial agents.

This study is devoted for empirical antibiotic treatment in the Urology Department of Belgorod Municipal Hospital No.2, in patients with calculous pyelonephritis, who have not received treatment with antibacterial drugs for the last 3 months, cefotaxime, ciprofloxacin and levofloxacin are recommended. For patients with calculous pyelonephritis who have been treated with antibacterial drugs for the last 3 months, amikacin, phosphomycin, piperacillin/tazobactam, cefoperazone/sulbactam, carbapenems are effective.

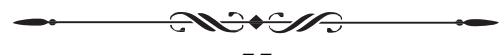


Ключевые слова: мочекаменная болезнь, калькулезный пиелонефрит, инфекиия мочевьводящих путей, чувствительность к антибиотикам, итаммы энтеробактерий.

\section{БИБЛИОГРАФИЧЕСКИЙ СПИСОК}

[1] Дутов В.В., Русанова Е.В., Румянцев А.А. Метаморфозы современной диагностики калькулезного пиелонефрита // РМЖ. 2014. №29. С. 2087-2088.

[2] Палагин И.С., Сухорукова М.В., Дехнич А.В. Эйдельштейн М.В.,Гринев А.В., Перепанова Т.С., Козлов P.С. Современное состояние антибиотикорезистентности возбудителей внебольничных инфекций мочевых путей в России: результаты исследования «ДАРМИС» (2010-2011) // Клиническая микробиология и антимикробная химиотерапия. 2012. Т. 14., № 4. С. 280-302.

[3] Critchley I. A., Cotroneo N., Pucci M. J., Mendes R. The burden of antimicrobial resistance among urinary tract isolates of Escherichia coli in the United States in 2017 // PLoS ONE.2019. 14, 12. p. e0220265. https://doi.org/10.1371/journal.pone.0220265

[4] Filippenko N, Malorodova T, Pokrovskaya T, Batishchev S, Balamutova T, Lihodedova V, Urozhevskaya Z. Approaches to antibiotic therapy in patients with calculous pyelonephritis, undergoing in-patient treatment in the department of urology. Research Results in Pharmacology. 2017. 3, №1 p. 73-78. https://doi.org/10.18413/2500235X-2017-3-1-73-78

[5] Chuhareva N.A., Bontsevich R.A., Shchurovskaya K.V., Denisova D.S. The choice of antimicrobial therapy among physicians in the treatment of gestational pyelonephritis // Research result: pharmacology and clinical pharmacology. 2016. Vol. 2, №3 P. 46-50. doi: 10.18413/2500-235X-2016-2-3-46-50.

[6] Малородова Т.Н., Покровская Т.Г., Смирнов А.А., Урожевская Ж.С., Кульченкова Т.И., Лиходедова В.П. Подходы к выбору стартовой антибактериальной терапии у пациентов с синдромом диабетической стопы, находящихся на лечении в Белгородской областной клинической больницеСвятителя Иоасафа // Журнал научных статей Здоровье и образование в XXI веке. 2017. T. 19. № $5 . \quad$ С. $106-112$. http://dx.doi.org/10.26787/nydha-2226-7425-2017-19-5106-112

[7] Pokrovskii M.V, Korokin MV, Kudryavtsev KV, Pokrovskaya TG, Gudyrev OS, Gureev VV, Korokina LV, Povetkin SV (2017) Study of Endothelial Protective Activity of Phenol-Derived Thrombin and Arginase-2 Inhibitors KUD-259 and KUD-974. Bulletin of Experimental Biology and Medicine 163(4): 436-438 https://doi.org/10.1007/s10517-017-3822-y

[8] Danilenko L.M., Pokrovskiy M.V. 3-(2,2,2-Trimethylhydrazinium) propionate: new concept of realization of cardioprotective effect // Research Journal of Pharmaceutical, Biological and Chemical Sciences. 2014. 5. № 6. C. 1419-1422.

[9] Danilenko L.M. Doxorubicin-associated cardiomyopathy: new approaches to pharmacological correction using 3-(2,2,2-trimethylhydrazinium) propionate derivatives // Research Results in Pharmacology. 2018. T. 4. № 1. C. 81-86. DOI 10.3897/rrpharmacology.4.25530

[10] Дутов В.В., Буймистр С.Ю., Русанова Е.В. Изменение микрофлоры мочи у пациентов с мочекаменной
Keywords: urolithiasis, calculous pyelonephritis, urinary tract infections, antibiotic sensitivity, strains of Enterobacteriacae.

\section{REFERENCES}

[1] Dutov V.V., Rusanava E.V., Rumyanstev A. A. (2014). Metamorphosis modern diagnosis of calculous pyelonephritis. Russian medical journal. 2014. 29. p. 2087-2088.

[2] Sukhorukova M. V., Edelstein M. V., Ivanchik N. V. Antimicrobial resistance of nosocomial Enterobacterales isolates in Russia: results of multicenter epidemiological study "MARATHON 2015-2016". Clinical Microbiology and Antimicrobial Chemotherapy. 2019. 16, 4. p. 254-265.

[3] Critchley I. A., Cotroneo, N, Pucci, M. J., Mendes, R. The burden of antimicrobial resistance among urinary tract isolates of Escherichia coli in the United States in 2017. 2019. PLoS ONE 14(12): e0220265. https://doi.org/10.1371/journal.pone. 0220265

[4] Filippenko N, Malorodova T, Pokrovskaya T, Batishchev S, Balamutova T, Lihodedova V, Urozhevskaya Z (2017). Approaches to antibiotic therapy in patients with calculous pyelonephritis, undergoing in-patient treatment in the department of urology. Research Results in Pharmacology 3(1): 73-78. https://doi.org/10.18413/2500-235X-2017-3-1-73-78

[5] Chuhareva N., Bontsevich R., Shchurovskaya K., Lysenko A. The choice of antimicrobial therapy among physicians in the treatment of gestational pyelonephritis. Research Results in Pharmacology. 2016. 2(3). p. 46-50. https://doi.org/10.18413/2500-235X-2016-2-3-46-50

[6] Malorodova T.N., Pokrovskaya T.G., Smirnov A.A., Urojevskaya J.S., Kulchenkova T.I., Lihodedova V.P. Antibacterial therapy in patients with diabetic foot syndrome undergoing in-patient treatment in st. Joseph belgorod regional clinical hospital The Journal of scientific articles "Health and Education Millennium", 2017. Vol. 19. No 5. p. 106-112. http://dx.doi.org/10.26787/nydha-2226-7425-2017-19-5106-112

[7] Pokrovskii M.V., Korokin M.V., Kudryavtsev K.V., Pokrovskaya T.G., Gudyrev O.S., Gureev V.V., Korokina L.V., Povetkin S.V. Study of Endothelial Protective Activity of Phenol-Derived Thrombin and Arginase-2 Inhibitors KUD-259 and KUD-974. Bulletin of Experimental Biology and Medicine. 2017. 163(4). p. 436-438 https://doi.org/10.1007/s10517-017-3822-y

[8] Danilenko L.M., Pokrovskiy M.V. 3-(2,2,2-Trimethylhydrazinium) propionate: new concept of realization of cardioprotective effect Research Journal of Pharmaceutical, Biological and Chemical Sciences. 2014. T. 5. № 6. C. 1419-1422.

[9] Danilenko L.M. Doxorubicin-associated cardiomyopathy: new approaches to pharmacological correction using 3(2,2,2-trimethylhydrazinium) propionate derivatives. Research Results in Pharmacology. 2018. T. 4. № 1. C. 81-86. DOI 10.3897/rrpharmacology.4.25530.

[10] Dutov V.V., Buymistr, S.Y., \& Rusanova, E.V. The changes in urine microflora in patients with urinary stone disease. $\begin{array}{lllll}\text { Urologiia. } & 2018 . & 6 . & \text { p. } & 32-36 .\end{array}$ DOI: https://dx.doi.org/10.18565/urology.2018.6.32-36

[11] Sursyakova K.I., Safyanova, T.V. Some epidemiological aspects of urinary tract infections in altai regional hospital for veterans of wars. Urologiia. 2018. 6. p. 76-79. DOI: https://dx.doi.org/10.18565/urology.2018.6.76-79

[12] Batishcheva G., Malorodova T., Pokrovskaya T., Kazakova E., Urozhevskaya Z., Zhernakova N., Osipova O. Analysis of

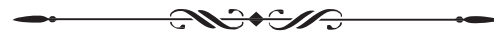


болезнью // Урология 2018. 6. с. 32-36. DOI: https://dx.doi.org/10.18565/urology.2018.6.32-36

[11] Сурсякова К.И., Сафьянова Т.В. Некоторые эпидемиологические аспекты инфекций мочевыводящих путей на примере крупных стационаров Алтайского края// Урология 2018. 6. с. 76-79. DOI: https://dx.doi.org/10.18565/urology.2018.6.76-79

[12] Batishcheva G, Malorodova T, Pokrovskaya T, Kazakova E, Urozhevskaya Z, Zhernakova N, Osipova O. Analysis of dynamics of antibiotic resistance of pathogens in patients with diabetic foot syndrome undergoing in-patient treatment // Research Results in Pharmacology. 2016. 2(1). p. 46-51. https://doi.org/10.18413/2313-89712016-2-1-46-51

[13] Перепанова Т.С., Козлов Р.С., Руднов. Федеральные клинические рекомендации «Антимикробная терапия и профилактика инфекций почек, мочевыводящих путей и мужских половых органов - 2015 г.» // Терапевтический архив. 2016. 88, 4 с. 100-104. DOI: 10.17116/terarkh2016884100-104

[14] Программа СКАТ (Стратегия Контроля Антимикробной Терапии) при оказании стационарной медицинской помощи: Российские клинические рекомендации. Под ред. С. В. Яковлева, Н. И. Брико, С. В. Сидоренко, Д. Н. Проценко. - М.: Издательство «Перо», 2018. $-156 \mathrm{c}$. dynamics of antibiotic resistance of pathogens in patients with diabetic foot syndrome undergoing in-patient treatment. Research Results in Pharmacology. 2016. 2(1) p. 4651. https://doi.org/10.18413/2313-8971-2016-2-1-46-51

[13] Perepanova T.S., Kozlov R.S., Rudnov V.A. Antimicrobial therapy and prevention of infections of the kidneys, urinary tract and the male reproductive organs. National guidelines of the Russian Society of Urology. Moscow, 2015, 72 p.

[14] The SKAT Program (Antimicrobial Therapy Control Strategy) for inpatient care: Russian Clinical Recommendations / Ed. S.V. Yakovleva, N.I. Briko, S.V. Sidorenko, D.N. Protsenko. - M.: Publishing House "Perot", 2018. - 156 p.

Author Contributions Malorodova T.N. - literature review, writing a text, research concept and design; Stepenko Yu.V. - collection and processing of materials; Bocharnikova T.V. — statistical data processing; Mikhailova Yu.A. — statistical data processing. Conflict of Interest Statement. The authors declare no conflict of interest.

Malorodova T.N. - SPIN-ID: 8280-8237; ORCID ID: 0000-0002-4186-2577

Research interests, number of main publications: Study of clinical pharmacology, cardiology, more than 30 publications were published, 5 of them in SCOPUS., 19 in the Higher Attestation Commission and 10 in conference proceedings.

Stepenko Yu.V. - SPIN-ID: 8192-8192; ORCID ID: 0000-0002-7414-7326

Research interests, number of main publications: Study of clinical pharmacology, cardiology, 3 publications were published, 1 of them in SCOPUS, 1 in the Higher Attestation Commission and 6 in conference proceedings.

Anikanova T.V. - ORCID ID: 0000-0002-8122-3382

Research interests, number of main publications: Study of cardiology, clinical pharmacology, 2 publication were published, 1 in the Higher Attestation Commission and 1 in conference proceedings.

Mikhailova Yu.A. - ORCID ID: 0000-0002-1103-6266

Research interests, number of main publications: Study of cardiology, clinical pharmacology, 1 publication was published in the Higher Attestation Commission.

Вклад авторов. Малородова Т.Н. - обзор литературы, написание текста, концепция и дизайн исследования Степенко Ю.В. - сбор и обработка материалов; Бочарникова Т.В. - статистическая обработка данных; Михайлова Ю.А. — статистическая обработка данных.

Заявление о конфликте интересов. Авторы заявляют об отсутствии конфликта интересов.

Малородова T.H. — SPIN-код: 8280-8237; ORCID ID: 0000-0002-4186-2577

Сфера научных интересов, количество основных публикаций: клиническая фармаколгия, кардиология, опубликованы более 30 публикаций из них 5 в СКОПУС, , 19 в ВАК и 10 в материалах конференций.

Степенко Ю.В. - SPIN-код: 8192-8192; ORCID ID: 0000-0002-7414-7326

Сфера научных интересов, количество основных публикаций: : клиническая фармаколгия, кардиология, опубликованы 8 публикаций из них 1 в СКОПУС, 1 в ВАК и 6 в материалах конференций.

Анииканова T.B. - ORCID ID: 0000-0002-8122-3382

Сфера научных интересов, количество основных публикаций: клиническая фармакология, опубликованы 2 публикации из них 1 в ВАК и 1 в материалах конференций.

Михайлова Ю.A. - ORCID ID: 0000-0041-7571-9760

Сфера научных интересов, количество основных публикаций: клиническая фармакология, кардиология, опубликована 1 в $B A K$.

Введение. Мочекаменная болезнь встречается более чем у 5\% населения России и является одним из самых распространенных и частых заболеваний в мире (5-
10\%), которая осложняется калькулезным пиелонефритом от $43-81 \%$ до $100 \%$ случаев [1]. В настоящее время, при относительно хорошей изученности

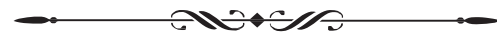


этиологической структуры возбудителей пиелонефрита, возникает быстрый рост резистентности к антибактериальных препаратам возбудителей, выделяемым при данном заболевании. Это превратило рациональные схемы лечения, применяемые в прошлом в неэффективные в настоящее время $[2,3,4]$, что требует оптимизации подходов к комплексной фармакотерапии $[5,6]$. Доклинические исследования на клеточном, молекулярном, органном, системном и организменном уровнях являются неотъемлемой частью изучения инновационных лекарственных средств $[7,8,9]$.

Результаты лечения зависят от рационально подобранной стартовой этиотропной антибактериальной терапии. При выборе терапии необходимо опираться на местные данные, полученные в конкретной больнице. $[10,11,12]$. Это делает необходимым проведение эпидемиологических исследований для определения структуры выделенных микроорганизмов и их чувствительности у пациентов с калькулезным пиелонефритом в отделении урологии Городской больницы №2, г. Белгород.

Цель данного исследования - изучение структуры выделенных микроорганизмов и их чувствительности к антибиотикам у пациентов с калькулезным пиелонефритом, находившихся на лечении в отделении урологии в 2017-2019 гг., а также определение чувствительности к антибактериальным химиотерапевтическим препаратам для стартовой терапии в в отделении урологии Городской больницы №2, г. Белгород.

Материалы и методы. Проведено ретроспективное фармакоэпидемиологическое исследование, в которое включены истории болезни пациентов мужского и женского пола старше 18 лет с установленным диагнозом «калькулезный пиелонефрит» при выделении возбудителя в диагностически значимом титре согласно

рекомендациям Российской Урологической Ассоциации [13].

Проанализированы 2410 историй пациентов (41,3\%, из них мужчин и 58,7\% - женщин; средний возраст пациентов 56,38 $\pm 6,8$ лет) с калькулезным пиелонефритом, которые находились на лечении в урологическом отделении Городской больницы №2 г.Белгород в 2017 2019 гг.

Всем пациентам проведено стандартное клиническое обследование, с обязательным бактериологическим исследованием мочи на чувствительность к антибиотикам и ультразвуковым исследованием почек. Клиническим материалом для исследования являлась средняя порция утренней свободно выпущенной мочи, полученная после туалета половых органов, либо после дренирования их катетером-стентом, или по дренирующему мочеточниковому катетеру/нефростоме. Образцы, которые показали рост более чем одного типа организмов, рассматривались как контаминация образца мочи, пациент исключался из исследования.

Проводилась идентификация штаммов микроорганизмов, полученных из мочи больных с калькулезным пиелонефритом, находившихся на лечении в урологическом отделении Городской больницы №2 г. Белгород в 2017-2019 годах. Тестирование чувствительности проводилось методом дисковой диффузии и интерпретировалось в соответствии с критериями EUCAST. Статистический анализ проводился с использованием прикладного статистического программного пакета «Statistica 10.0». Результаты и обсуждение. За период 2017-2019 гг. выделены 723 штамма (32,1\%) из мочи из 2410 пациентов с калькулезным пиелонефритом, проходивших лечение в урологическом отделении Городской больницы №2 г. Белгород (таблица 1).

Таблица 1

Частота выделения грамотрицательных бактериальных возбудителей у пациентов с калькулезным пиелонефритом за период 2017-2019

\begin{tabular}{|l|c|c|c|c|}
\hline \multirow{2}{*}{ Возбудитель } & \multicolumn{3}{|c|}{ Число изолированных штаммов } \\
\cline { 2 - 5 } & 2017 & 2018 & 2019 & Всего \\
\hline Escherichia coli. & 147 & 117 & 204 & 468 \\
\hline Enterobacter spp. & - & - & 7 & 7 \\
\hline Klebsiella spp. & 62 & 79 & 21 & 162 \\
\hline Proteus mirabilis & 14 & 15 & 11 & 40 \\
\hline Pseudomonas aeruginoza & 5 & 2 & - & 7 \\
\hline Enterococcus spp. & 11 & 13 & 15 & 39 \\
\hline Всего & 239 & 226 & 258 & 723 \\
\hline
\end{tabular}

Frequency of isolated bacterial pathogens isolated from patients

Table 1 with calculous pyelonephritis in 2017-2019

\begin{tabular}{|l|c|c|c|c|}
\hline \multirow{2}{*}{ Pathogens } & \multicolumn{3}{|c|}{ Number of isolated strains } \\
\cline { 2 - 5 } & 2017 & 2018 & 2019 & 204 \\
\hline Escherichia coli. & 147 & 117 & 7 & 468 \\
\hline Enterobacter spp. & - & - & 21 & 7 \\
\hline Klebsiella spp. & 62 & 79 & 162 \\
\hline Proteus mirabilis & 14 & 15 & 40 \\
\hline
\end{tabular}

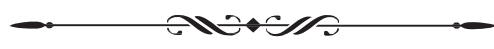

$\sim 58 \sim$ 


\begin{tabular}{|c|c|c|c|c|}
\hline Pseudomonas aeruginoza & 5 & 2 & - & 7 \\
\hline Enterococcus spp. & 11 & 13 & 15 & 39 \\
\hline Total & 239 & 226 & 258 & 723 \\
\hline
\end{tabular}

Наши данные показали более высокую распространенность грамотрицательных бактерий, представленных штаммами энтеробактерий. Наиболее репрезентативными микроорганизмами были Escherichia coli, выделенная в 64,7\% случаев. затем Klebsiella spp. в 22,4\% случаев, Proteus. mirabilis в 5,5\% случаев и виды Enterobacter в 1,0\% случаев. Частота выделения для видов Pseudomonas spp. составляла 1,0\% случаев, для Enterococcus spp. было 5,4\% случаев.

В связи с доминированием штаммов Enterobacterales в этиологической структуре возбудителей при калькулезном пиелонефрите наибольший интерес представляют данные об общей чувствительности всех выделенных штаммов Enterobacterales.

Наиболее эффективными агентами для всех штаммов выделенных энтеробактерий были карбапенемы: все изоляты проявляли чувствительность к карбапенемам, кроме 1 штамма Enterobacter cloacae, который был резистентен к эртапенему (99,6\% случаев), но чувствительность к меропенему зарегистрирована в 100\% случаев. Чувствительность изолированных энтеробактерий к ампициллину составила в 29,6\% случаев, 24,6\% случаев, 27,6\% случаев; к амоксициллин / клавуланату - в 46,6\% случаев, 36\% случаев, $41,2 \%$ случаев, к цефотаксиму - в 61,0\% случаев, 49,8\% случаев, 64,2\% случаев, к цефтазидиму - в 64,1\% случаев, 50,7 \% случаев, $67,9 \%$ случаев, к цефепиму - 65,5\% случаев, $54,0 \%$ случаев, 69,6\% случаев в 2017, 2018, 2019 гг. соответственно. Активность ципрофлоксацина выявлена в $70,0 \%$ случаев, $64,0 \%$ случаев, $71,2 \%$ случаев в 2017 , 2018 и 2019 гг. соответственно. Чувствительность к котримоксазолу варьировала от 49,3\% случаев до 57,2\% случаев в 2017-2019 гг. Выявлена высокая активность амикацина: в 2017 г. чувствительность к амикацину составила 93,3\%, в 2018 г. - 91,0\%, в 2019 г. - 93,4\%. Зарегистрирована более низкая чувствительность к гентамицину по сравнению с амикацином. Установлено, что $73,1 \%$ изолятов, $70,1 \%$ изолятов, $74,9 \%$ изолятов чувствительны к гентамицину в 2017, 2018 и 2019 гг. соответственно. Высокоэффективными агентами был фосфомицин. Его активность зарегистрирована в $87,9 \%$ случаев, в $81,5 \%$ случаев, в 93,4\% случаев в 2017, 2018, 2019 годах соответственно.

Среди грамположительных бактерий наиболее частым патогеном был Enterococcus spp. (5,4\% случаев), что ниже уровня, полученного другими российскими исследователями [12].
Для разработки рекомендаций стартовой антибактериальной терапии в соответствии с программой СКАТ и стратификацией пациентов по уровню резистентности микроорганизмов в нашем исследовании проанализирован уровень резистентности выделенных штаммов энтеробактерий у пациентов, находящихся на лечении в урологическом отделении ОГБУЗ «Городская больница №2 г.Белгорода» в 2019 г., в зависимости от предшествующего приема антибактериальных препаратов в предыдущие 3 месяца: тип I - пациенты, не получавшие антибактериальные препараты в предшествующие 3 месяца и без других факторов риска полирезистентных возбудителей, тип II - пациенты, получавшие антибактериальные препараты в предшествующие 3 месяца или другие факторы риска полирезистентных возбудителей [14].

Проанализирована частота выделяемых микроорганизмов у пациентов с калькулезным пиелонефритом в урологическом отделении Городской больницы №2 г. Белгород в 2019 г. в зависимости от предшествующего лечения антибактериальными препаратами. Зарегистрировано, что 71,2\% изолятов Escherichia coli выявлены у пациентов, которые не получали антибактериальные терапию по сравнению с $28,8 \%$ штаммов Escherichia coli, выделенные у пациентов, получавших антибактериальную терапию в предшествующие 3 месяца. Напротив, процентное соотношение частоты выделения штаммов Klebsiella spp. и Enterobacter spp. было выше у пацинтов, получавших антибактериальную терапию $(66,7 \%$ и $71,4 \%$, соответственно) (p $<0,01)$.

При анализе чувствительности выделенных штаммов Enterobacteriaceae, в зависимости от предшествующей терапии антибактериальными препаратами в предыдущие 3 месяца выявлена достоверная разница между чувствительностью штаммов Enterobacteriaceae, выделенных у пациентов не получавших антибактериальную терапию, и штаммов Enterobacteriaceae, выделенными у пациентов, получавших терапию антибактериальными препаратами к амоксициллину/клавуланату (56,6\% и $6,5 \%$ соответственно, $\mathrm{p}<0,001)$, цефотаксиму $(85,5 \%$ и $23,4 \%$ соответственно, $<<0,001)$, цефтазидиму $(86,7 \%$ и $24,7 \%$ соответственно, $\mathrm{p}<0,001)$, цефепиму ( $87,3 \%$ и $26,0 \%$ соответственно, $\mathrm{p}<0,001)$, ципрофлоксацину $(85,5 \%$ случаев и $42,9 \%$ случаев соответственно, $\mathrm{p}<0,001$; ко-тримоксазола - 72,9\% случаев и $32,5 \%$ случаев соответственно, $\mathrm{p}<0,001$ (таблица 2).

\section{Таблица 2}

Чувствительность штаммов Enterobacterases, в зависимости от предшествующего применения антибиотикв, выделенных у пациентов с калькулезным пиелонефритом в 2019 г.

\begin{tabular}{|c|c|c|c|c|c|c|}
\hline Pathogens & Total & $\%$ & Группа I* & $\%$ & Группа II** & $\%$ \\
\hline Total (\%) & 243 & 100.0 & 166 & 68.3 & 77 & 31.7 \\
\hline
\end{tabular}

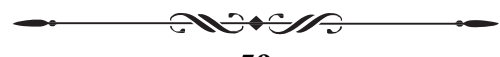




\begin{tabular}{|l|c|c|c|c|c|c|}
\hline Amoxicillin / clavulanate & 99 & 40.7 & 94 & 56.6 & 5 & 6.5 \\
\hline Cefotaxime & 160 & 65.8 & 144 & 85.5 & 18 & 23.4 \\
\hline Ceftazidime & 164 & 67.5 & 146 & 86.7 & 19 & 24.7 \\
\hline Cefepime & 166 & 68.3 & 148 & 87.3 & 20 & 26.0 \\
\hline Meropenem & 243 & 100.0 & 166 & 100.0 & 77 & 100.0 \\
\hline Ertapenem & 242 & 99.6 & 166 & 100.0 & 76 & 98.7 \\
\hline Gentamicin & 178 & 73.3 & 131 & 81.3 & 43 & 55.8 \\
\hline Amikacin & 228 & 93.8 & 164 & 98.8 & 64 & 83.1 \\
\hline Ciprofloxacin & 175 & 72.0 & 140 & 85.5 & 33 & 42.9 \\
\hline Co-trimoxazole & 145 & 59.7 & 142 & 72.9 & 25 & 32.5 \\
\hline Fosfomycin & 227 & 93.4 & 121 & 98.8 & 63 & 81.8 \\
\hline
\end{tabular}

*Группа I - пациенты, не получавшие антибактериальные препараты в предшествующие 3 месяца,

**Группа II - пациенты, получавщие антибактериальные препараты в предшествующие 3 месяца или имеющие другие факторы риска полирезистентных возбудителей

Table 2

Susceptibility of Enterobacterases, depending on the previous use of antibiotics isolated in patients with calculous pyelonephritis in 2019

\begin{tabular}{|l|c|c|c|c|c|c|}
\hline \multicolumn{1}{|c|}{ Pathogens } & Total & $\%$ & Group I* & $\%$ & Group II** & $\%$ \\
\hline Total (\%) & 243 & 100.0 & 166 & 68.3 & 77 & 31.7 \\
\hline Amoxicillin / clavulanate & 99 & 40.7 & 94 & 56.6 & 5 & 6.5 \\
\hline Cefotaxime & 160 & 65.8 & 144 & 85.5 & 18 & 23.4 \\
\hline Ceftazidime & 164 & 67.5 & 146 & 86.7 & 19 & 24.7 \\
\hline Cefepime & 166 & 68.3 & 148 & 87.3 & 20 & 26.0 \\
\hline Meropenem & 243 & 100.0 & 166 & 100.0 & 77 & 100.0 \\
\hline Ertapenem & 242 & 99.6 & 166 & 100.0 & 76 & 98.7 \\
\hline Gentamicin & 178 & 73.3 & 131 & 81.3 & 43 & 55.8 \\
\hline Amikacin & 228 & 93.8 & 164 & 98.8 & 64 & 83.1 \\
\hline Ciprofloxacin & 175 & 72.0 & 140 & 85.5 & 33 & 42.9 \\
\hline Co-trimoxazole & 145 & 59.7 & 142 & 72.9 & 25 & 32.5 \\
\hline Fosfomycin & 227 & 93.4 & 121 & 98.8 & 63 & 81.8 \\
\hline
\end{tabular}

* Group I - patients who did not receive antibacterial drugs in the previous 3 months,

** Group II - patients who received antibacterial drugs in the previous 3 months or have other risk factors for multiresistant pathogens

Заключение.

1. Основными патогенными микроорганизмами, выделенными у пациентов с калькулезным пиелонефритом, находившихся на лечении в урологическом отделении Городской больницы №2 г.Белгорода в 2017-2019 гг., являлась Escherichia coli, представленная в 64,7\% случаев, Klebsiella spp. в 22,4\% случаев.

2. Наиболее активными антибиотиками у энтеробактерий являлись меропенем (100\% чувствительных изолятов), эртапенем (98,7-100\% чувствительных изолятов), амикацин $\quad(91,0-93,4 \%$ чувствительных изолятов),

фосфомицин (81,5-93,4\% чувствительных изолятетов) в 2017-2019 гг.

3. Для стартового эмпирического лечения антибиотиками в урологическом отделении Городской больницы №2 г. Белгород у пациентов с калькулезным пиелонефритом, не получавших лечение антибактериальными препаратами последние 3 месяца, рекомендован цефотаксим, ципрофлоксацин и левофлоксацин; у пациентов с калькулезным пиелонефритом, получавших лечение антибактериальными препаратами последние 3 месяца эффективны амикацин, фосфомицин, пиперациллин/тазобактам, цефоперазон/сульбактам, карбапенемы.

Ответственный за переписку: Малородова Татьяна Николаевна - кандидат медицинских наук доиент кафедры фаркмакологии и клинической фармакологии, ФГБОУ ВО «Белгородский государственный национальный исследовательский университет», г. Белгород,

Российская Федераиия, E-mail: malorodova tn@mail.ru Corresponding Author: Malorodova Tatyana Nikolaevna - kandidat of medical Sciences, Associate

Professor of the Department of pharmacology and clinical pharmacology, Belgorod State University, Belgorod, Russia, E-mail: malorodovatn@mail.ru

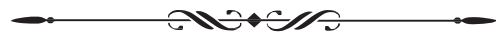

$\sim 60 \sim$ 